\title{
O AVESSO DO ESPLENDOR E OS RESTOS DO IMPÉRIO: A DESCOLONIZAÇÃO EM O ESPLENDOR DE PORTUGAL, DE LOBO ANTUNES
}

Leonardo von Pfeil Rommel ${ }^{1}$

\begin{abstract}
Resumo: O presente artigo analisa o romance $O$ esplendor de Portugal (1997), de autoria do escritor português António Lobo Antunes, quanto à sua particularidade em representar e problematizar a descolonização portuguesa em África. Por intermédio da literatura, Lobo Antunes busca dar voz aos colonos portugueses retornados, uma geração estigmatizada pela sociedade e pelo poder estatal português no período pós-Revolução dos Cravos. A literatura apresenta-se, assim, como espaço de questionamento da história e da identidade nacional portuguesa no período pós-imperial. A fim de refletir sobre o processo de descolonização e sobre a literatura pós-colonial, são utilizados autores como Eduardo Lourenço (2013) e Margarida Calafate Ribeiro (2006).

Palavras-chave: Descolonização; colonos retornados; pós-colonialismo; António Lobo Antunes.

\section{THE SPLENDOR'S AVERAGE AND THE REMAINS OF THE EMPIRE: THE DECOLONIZATION IN O ESPLENDOR DE PORTUGAL, BY LOBO ANTUNES}

\begin{abstract}
This article analyzes the novel O esplendor de Portugal (1997), authored by the Portuguese writer António Lobo Antunes as to its particularity in representing and problematizing the Portuguese decolonization of Africa. Through literature, Lobo Antunes seeks to give voice to Portuguese settlers returned from ex-colonies, a generation stigmatized by society and Portuguese state in the period after the Carnation Revolution. Literature thus presentes itself as a space for questioning Portuguese history and national identity in the post-imperial period. In order to reflect on the process of decolonization and on the post-colonial literature, authors like Eduardo Lourenço (2013) and Margarida Calafate Ribeiro (2006) are used.
\end{abstract}

Keywords: Decolonization; returned settlers; postcolonislim; António Lobo Antunes.

O presente artigo analisa o romance $O$ esplendor de Portugal, de autoria do escritor português António Lobo Antunes, quanto à sua particularidade em representar o processo de descolonização portuguesa em África, objetivando, assim, por meio do discurso literário, problematizar um dos capítulos mais conturbados da história nacional de Portugal. Décima segunda publicação do autor, lançado em 1997, 23 anos após a Revolução dos Cravos e o início da descolonização dos territórios portugueses em África, a narrativa revisita as traumáticas facetas que o acontecimento promoveu junto à sociedade reconfigurando o conceito de identidade nacional, dando voz àqueles que foram marginalizados: os colonos retornados.

\footnotetext{
${ }^{1}$ Doutorando em Estudos de Literatura - Universidade Federal do Rio Grande do Sul (UFRGS)
} 
A Revolução dos Cravos, ocorrida em Abril de 1974, foi responsável por assinalar o final da ditadura salazarista, que perdurava em Portugal por longas quatro décadas e era marcada por uma política fascista de fechamento nacional, que via na manutenção das colônias em África a pedra angular da sobrevivência econômica e identitária da nação. O final do sistema ditatorial, além de encerrar os combates da Guerra Colonial, travados desde o começo da década de 1960, com o intuito de cercear e extinguir os movimentos independentistas africanos, deu início ao processo de descolonização, o qual foi responsável por marcar o final do império português em África após cinco séculos.

A descolonização dos territórios ultramarinos trouxe a Portugal centenas de milhares de colonos portugueses, que, após as independências dos países africanos e a crescente violência dos conflitos armados, viram-se obrigados a abandonar suas vidas em África e rumar para a Europa. Como apontam alguns registros, estima-se que a partir de 1974 até o início da década de 1980 tenham emigrado para Portugal em torno de 600 mil portugueses. A descolonização assumiu-se, assim, como uma tragédia social sem precedentes, responsável por alterar de forma profunda a sociedade e o modo de pensar a identidade nacional.

O processo de descolonização, como aponta Eduardo Lourenço (2013), processouse de forma extremamente rápida, pois, após a Revolução dos Cravos, o novo governo revolucionário pretendia apagar a memória do antigo regime ditatorial, a fim de superar o passado opressivo e isolacionista do país, almejando que Portugal efetuasse uma aproximação do bloco de países europeus, como forma de alterar a imagem nacional e buscar a sua modernização econômica e social. A rápida descolonização dos territórios ultramarinos na África sofreu, assim, perante a sociedade portuguesa, um processo de apagamento da memória coletiva sem que houvesse nenhum tipo de problematização da situação. Conforme Eduardo Lourenço:

A fabulosa rapidez com que a descolonização se efectuou também não alterou esta nova imagem, antes pareceu reforçá-la, em particular aos olhos da esquerda portuguesa, que é então a única força política actuante e que conta. Será para sempre um assunto de reflexão interminável o do (aparente?) desinteresse com que a generalidade do povo português (...) aceita desfazer-se em escassos meses de territórios de considerável interesse económico e estratégico e em circunstâncias de completo descontrole, nos quais havia suportado uma luta de treze anos e cuja imagem fazia parte integrante (ou parecia fazer) da sua própria imagem de povo colonizador por excelência, atributo e núcleo central da mitologia do antigo regime, mas também de todo o passado nacional (LOURENÇO, 2013, p. 63). 
Ainda segundo Eduardo Lourenço (2013), o abandono dos 500 anos de existência imperial de Portugal foi vivido pela sociedade portuguesa de forma muito peculiar. A antiga imagem de país imperialista e navegador que compunha ativamente o imaginário nacional, após abril de 1974, foi substituída pacificamente e sem sobressaltos pela nova imagem de país democrático e revolucionário. A respeito da descolonização, como sugere o autor, "tudo pareceu passar-se como se jamais tivéssemos tido essa famigerada existência 'imperial' e em nada nos afectasse o regresso aos estreitos e morenos muros da 'pequena casa lusitana”'. (LOURENÇO, 2013, p. 43).

No Portugal pós-Revolução, como aponta a jornalista Helena Matos (2014), o governo tentava controlar e mascarar o processo de descolonização, censurando a imprensa para que evitasse abordar a temática, o que fez com que os retornados que começaram a chegar aos milhares no país, após este período, fossem silenciados e tornados anônimos. Como aponta a autora, "do ponto de vista informativo, os retornados enfrentarão vários muros de silêncio e preconceito" (MATOS, 2014, p. 14), impostos pelo novo governo e pela ainda ativa memória do antigo regime salazarista.

Em 1975 os retornados já não eram um fenómeno que se pudesse iludir. Eles já estavam a chegar. Simplesmente os jornalistas não os mostravam. $\mathrm{E}$ os dirigentes políticos e militares faziam de conta que não os viam e escondiam dos portugueses aquilo que já sabiam estar a começar em África: o maior êxodo da História de Portugal (MATOS, 2015, p. 04).

Com sua existência negligenciada pelo poder estatal e pela mídia, os colonos retornados acabam por ser estigmatizados pela sociedade portuguesa após o seu regresso das ex-colônias africanas, sendo relegados a uma espécie de "entre-lugar" da história nacional, desempenhando o papel de restos do império, uma vez que sua presença na metrópole se apresenta como extremamente perturbadora para a nova imagem que o país buscava concretizar após a Revolução. Os retornados tornam-se, assim, uma geração que não pertence a tempo algum, pois não pertencem mais à África, local onde muitos nasceram e se estabeleceram e também não pertencem a Portugal, local onde não mais encontram espaço.

Em entrevista a Jeferson Del Rios (2000), Lobo Antunes comenta que a descolonização foi uma situação esquizofrênica, pois milhares de pessoas foram obrigadas a efetuar uma viagem incerta para um país que desconheciam ou sobre o qual possuíam apenas idealizações. Através da narrativa de $O$ esplendor de Portugal, Lobo Antunes converte 
em protagonistas sujeitos marginalizados e esquecidos pela sociedade no período pósRevolução dos Cravos. Mais de vinte anos após a descolonização, o romance atua como uma espécie de mea culpa coletivo que traz ao debate o passado traumático ainda vivo na sociedade portuguesa.

Com a independência, de repente um milhão de pessoas vieram para Portugal, lugar que elas não conheciam, porque muitas tinham nascido na África. Da noite para o dia, essas pessoas se viram num país que não sabiam o que era, um país que para elas era mítico. Uma situação esquizofrênica (ANTUNES, 2000, p. 84).

De acordo com a opinião de Lobo Antunes, a descolonização portuguesa da África caracterizou-se como um acontecimento social extremamente conturbado, pois em um curto espaço de tempo centenas de milhares de pessoas tiveram de abandonar sua vida na África e viram-se obrigadas a partir rumo ao desconhecido devido à situação caótica que se estabeleceu nas colônias após as independências, principalmente em Angola, local em que se desenvolve grande parte da narrativa do romance.

É justamente sobre as traumáticas mudanças sociais causadas pela descolonização que $O$ esplendor de Portugal situa sua narrativa. No romance, Lobo Antunes explora a trajetória de desagregação de uma família de colonos portugueses que vivia em Angola e que, após a Revolução e o início da guerra civil naquele país, vê-se obrigada a separar-se. Enquanto que os filhos Carlos, Rui e Clarisse emigram para Portugal a fim de fugirem da violência, Isilda, a matriarca da família, decide permanecer no país mesmo em meio aos conflitos com o objetivo de tentar assegurar a estabilidade das posses familiares.

O esplendor de Portugal, evocado pelo título do romance e tomado ao hino nacional português, que se apresenta como epígrafe da narrativa, segundo Graça Abreu (2009, p. 96) “esboroa-se na desagregação da família - avatar do falso brilho do império". A retomada do hino nacional no título do romance por parte de Lobo Antunes decorre de uma utilização irônica, pois na trajetória dos colonos portugueses por ele representados não há nada de glorioso a ser retomado, o passado apresenta-se como um tempo repleto de dores e traumas, tanto para os filhos, que abandonaram a África e sentem-se rejeitados em Portugal, como para Isilda, que permanece em Angola, mas assiste ao inevitável desmoronar de sua existência.

Nas páginas de $O$ esplendor de Portugal ecoam vozes e episódios sombrios do império português que apresentam o avesso, o lado antiépico das glórias passadas que são enaltecidas pelos famosos versos do hino nacional. Nas palavras de Costa (1997), o 
romance "é a versão bufa da epopeia que o hino anuncia. O 'nobre povo, nação valente e imortal' ganha, na recriação de Lobo Antunes, a dimensão rasteira e sem glória que nem a ilusão sustenta" (COSTA, 1997, p. 191).

Como aponta Maria Alzira Seixo (2002), em relação à representação da problemática da descolonização, O esplendor de Portugal é o romance "mais total e incisivo" da obra de Lobo Antunes, pois em sua tessitura polifônica encontra-se "a voz de queixa ou alheamento oriunda de África, isto é, a voz dos que lá nasceram e de lá partiram, ou que ficaram para partirem pela morte" (SEIXO, 2002, p. 319). O romance apresenta-se, assim, como a voz de uma geração, a dos colonos retornados, aqueles que foram os responsáveis por erguer a grandiosidade do império, mas que sofreram na carne as consequências do problemático término.

Segundo a perspectiva de Graça Abreu (2008), o romance apresenta "um panorama do colonialismo português do século XX, na perspectiva dos que lhe deram corpo, sem glória nem esplendor, em continuado e sórdido exercício de violentação de terras e gentes” (ABREU, 2008, p. 95), representando, assim, o obscuro resultado do colonialismo português em África, ou seja, a desagregação, a miséria, o racismo e a exploração das terras e povos originários do território africano e o drama que atingiu os colonos portugueses no momento do regresso à metrópole na Europa.

A narrativa inicia-se em um fictício 24 de dezembro de 1995, quando Carlos, junto com sua esposa Lena, também emigrada de Angola, aguardam pela visita de seus dois irmãos, Rui e Clarisse, para a ceia de Natal. A partir desse ponto, o romance divide-se em fragmentos de narrativas que comportam vozes e memórias que avançam e recuam no tempo em um processo constante de atualização do passado, recuperando, através do ponto de vista de cada um dos diferentes personagens, o conturbado passado familiar em Angola, marcado por traumas e escândalos diversos.

Através destas diferentes perspectivas e vozes, são revelados, além das faces obscuras da família, também os horrores do colonialismo e da presença portuguesa em África, marcada por violências extremas, racismo e exploração. A família de colonos representada acaba por apresentar-se como uma metáfora do império nacional, uma vez que ambas as estruturas sociais emergem como que repletos por ocultações, traumas e uma infindável rede de mentiras, responsável por dar sustentação à ilusória imagem de unidade e agregação. 
Carlos, "ser entre dois mundos e por ambos rejeitado, simultaneamente opressor e oprimido" (ABREU, 2008, p. 96) exerce um papel central na narrativa, pois vive em um constante entre-lugar, tanto no plano existencial como territorial. Desempenhando a figura de colono retornado, não se adapta a Portugal, mas também não sente saudades da África, por carregar consigo os traumas familiares e o estigma de ser mestiço. Fruto de uma relação extraconjugal de seu pai com uma negra é parcialmente integrado ao meio familiar por Isilda, para evitar um escândalo social e o término do casamento. Ciente desde a infância de sua condição marginalizada, rompe os laços afetivos tanto com os irmãos como com seu pai e sua mãe por sentir-se não aceito, mas simplesmente tolerado junto aos brancos.

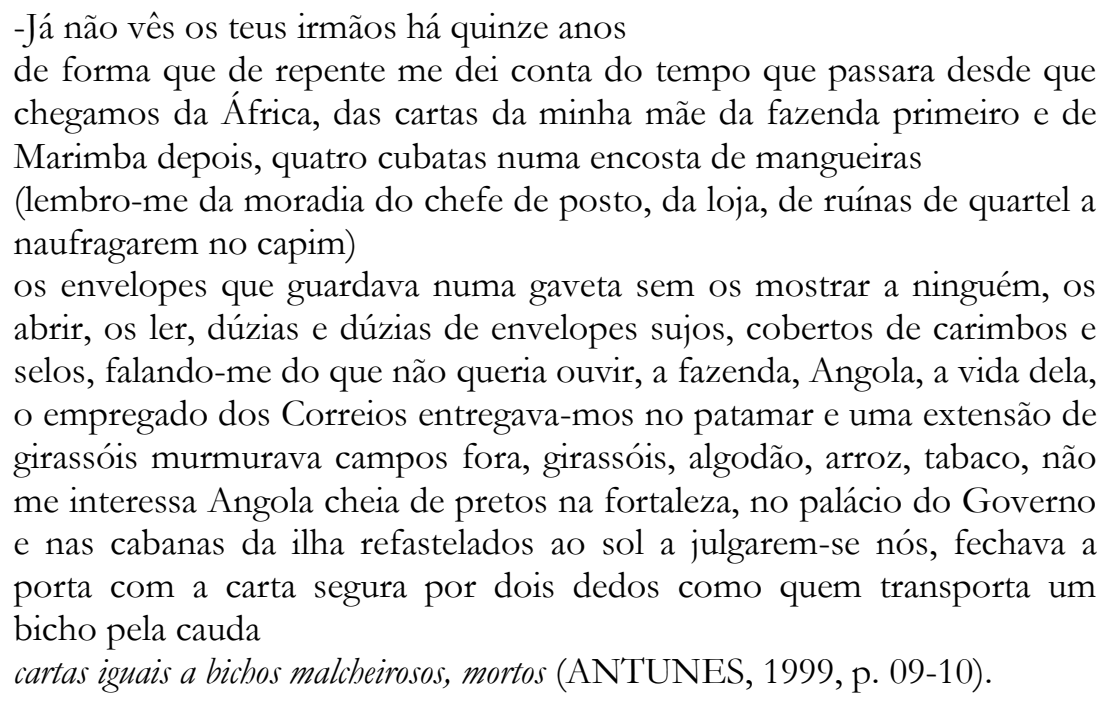

Neste diálogo com sua esposa Lena, a respeito do fato de não ver seus dois irmãos há quinze anos, desde que ele os expulsou do apartamento da família após a chegada da África, Carlos relembra as inúmeras cartas enviadas pela mãe, cartas estas que ele desprezava e não lia, renegando seu passado familiar e demonstrando um profundo sentimento de desinteresse por Angola, espaço onde nasceu e que marcou sua infância. $\mathrm{O}$ convite para a ceia de Natal trata-se de uma tentativa de apaziguar o passado após o rompimento dos laços com seus dois irmãos, após ter internado Rui, deficiente mental e epilético em uma clínica e expulsado Clarisse de casa.

Carlos mantém uma relação conturbada com sua própria esposa, Lena, quem ele acredita ter livrado da miséria da periferia de Malanje ao terem casado e ido morar na antiga fazenda. Ele nutre uma espécie de preconceito frente à sua mulher, pois acredita que ela, uma branca, aceitou casar-se com ele somente com o intuito de mudar de vida e abandonar a pobreza do musseque. No começo do relacionamento, demonstra diversas vezes sentir 
vergonha da namorada e teme ser visto em sua companhia no centro da cidade. Percebe-se, assim, que seu casamento com Lena é uma relação ambígua, permeada pela aceitação e pela rejeição mutuamente.

Carlos demonstra remorso da sua família por ser tratado de forma diferente, por ser rejeitado constantemente pela avó e por ser, de certa forma, tolerado, desde que não atrapalhasse a imagem da família e não provocasse nenhum escândalo, como seria caso fosse descoberto que ele era filho de uma relação anterior ao casamento do engenheiro português Amadeu, marido de Isilda, com uma negra, empregada da empresa onde o marido trabalhava. $\mathrm{O}$ racismo e a segregação que são constantes no romance refletem o status de uma sociedade dividida em raças, que cultuava a absurda superioridade dos brancos europeus frente aos negros africanos.

(...) no aniversário da minha avó os belgas enchiam-nos o vestíbulo de malas e ficavam uma semana a beber com o meu pai no terraço, a caçar jacarés na Chiquita, a usar fraque ao jantar como as mulheres deles penteados barrocos (...), os meus irmãos e eu comíamos num compartimento à parte por não haver lugar à mesa nem pela Clarisse nem pelo Rui era por medo que os estrangeiros reparassem que eu não era branco, era preto como os contratados, mal aparecíamos na varanda cheia de senhoras, sentadas a tomarem chá, de capacete colonial e botas de montar, fitando-nos num horror delicado, a minha mãe levantava-se logo abrindo as mangas a esconder-me, mandando-nos brincar para o jardim (...) a minha mãe que se a Clarisse ou o Rui entravam sozinhos na varanda os chamava, os deixava ficar, os mostrava às convidadas e se era eu as bochechas lhe caíam como se perdesse malares e me enxotava numa lufa-lufa antes que pudessem ver-me (...) (ANTUNES, 1999, p. 117).

Percebe-se, nesta passagem da narrativa, que o protagonista era excluído pelo seu meio familiar devido à sua cor e às suas origens, assim como ele passa a ser excluído também em Portugal, após a sua chegada da África. O romance de Lobo Antunes desvenda as contradições do império português e da descolonização. Os colonos retornados, ao desembarcarem na metrópole passam a viver em um entre-lugar, vivenciando uma situação extremamente ambígua, pois, apesar de serem portugueses, muitos haviam nascido na África e haviam constituído toda a sua vida e identidade no outro continente. O personagem Carlos representa esta ambiguidade, contradição causada pelo império colonial português, pois ele emerge como o representante de toda uma geração atingida pela descolonização.

Assim como o irmão, Rui e Clarisse também guardam recordações traumáticas da péssima relação familiar. Rui, acometido pela epilepsia e por problemas psiquiátricos que o 
incapacitam de ter uma vida normal, atua na narrativa como uma espécie de observador, responsável por registrar momentos obscuros da família. É através de seu olhar que emergem revelações sobre a grande teia de mentiras e falsidades que cercava o núcleo familiar, como a relação extraconjugal de Isilda com o inspetor de polícia, o aborto clandestino da irmã durante a adolescência e a dramática destruição do pai, Amadeu, consumido pelo vício do álcool. Em passagem de 24 de dezembro de 1995, Rui relembra a discriminação racial que a família impunha constantemente a Carlos, relevando sua existência a um constante incômodo.

Como a minha irmã Clarisse costumava dizer no fundo tenho pena dele, sempre trancado no apartamento da Ajuda olhando o rio por um intervalo de cortinas a pensar em Angola, esperando que a Maria da Boa Morte o chame

- Menino

para the dar banho, servir o almoço, oferecer às escondidas as guloseimas que fazia em segredo para ele (...), a minha avó a aparecer de repente na cozinha tratando-o conforme tratava os bailundos, na mesma impaciência exasperada

- O quê andas a comer Carlos?

sem que eu entendesse a razão da sua fúria, a minha avó para a minha mãe à noite, quando julgava que estávamos deitados e não ouvíamos

- É uma vergonha para a família tê-lo em casa Isilda só Deus sabe a vergonha que sinto

o meu pai na trincheira do jornal, o pêndulo do relógio no silêncio (...). (ANTUNES, 1999, p. 182).

Clarisse, criada em Angola como menina rica, sem jamais ter compromissos e dispondo de tudo que desejasse prontamente, ao chegar a Portugal, deparara-se com uma nova realidade. A vida de herdeira de terras é substituída por uma existência melancólica, permeada pelas lembranças do passado e da infância. Como forma de manter-se em Lisboa, após ser expulsa por Carlos do apartamento da família, passa a arranjar-se como amante de empresários e políticos, que lhe sustentam os gastos supérfluos com roupas e jóias e vão preenchendo sua vida por promessas vãs de casamento e união estável.

Isilda, a matriarca, exerce um papel fundamental na narrativa, pois ela representa $\mathrm{O}$ anacronismo do colonialismo português. Filha de colonos que emigraram de Portugal para buscar riqueza e poder na África, seu discurso nega a realidade, e, a fim de conformar-se com o novo tempo pós-colonial, um tempo em que o império português chegou ao seu fim, ela fecha-se em seu mundo particular, rememorando os tempos de glória da família, quando mandavam e exerciam um papel de destaque entre os negros africanos. 
Após enviar os filhos para Lisboa, permanece sozinha com os criados na fazenda, agora impossibilitada de gerir lucros e produzir, devido à guerra civil e ao processo de degradação que o conflito trouxe ao novo país. A Angola pós-colonial apresenta-se como um palco de disputas entre forças que se debatem pelo direito a comandar os restos e escombros deixados pela exploração do colonialismo português. Sozinha e desiludida, Isilda reinventa o passado glorioso, os áureos tempos da dominação e riqueza a fim de escapar da dura realidade de miséria e violência.

Compreendi que a casa estava morta quando os mortos principiaram a morrer. O meu filho Carlos, em criança, julgava que o relógio de parede era o coração do mundo, o verdadeiro coração do mundo não estava ali conosco mas além do pátio e do bosque de sequóias, no cemitério onde no tempo do meu pai enterravam lado a lado os pretos e os brancos do mesmo modo que antes do meu pai, na época do primeiro dono do girassol e do algodão, sepultaram os brancos que passavam a cavalo e davam ordens e os pretos que trabalhavam nas lavras neste século e no anterior ainda (...). O autêntico coração da casa eram as ervas sobre as campas ao fim da tarde ou no princípio da noite, dizendo palavras que eu entendia mal por medo de entender, não o vento, não as folhas, vozes que contavam uma história sem sentido de gente e bichos e assassínios e guerra como se segredassem sem parar a nossa culpa, nos acusassem, repetindo mentiras, que a minha família e a família antes da minha tinham chegado como salteadores e destruído a África, o meu pai aconselhou

- Não ouças.

Visto que moro no que me pertence, na quinta que fizemos e me pertence como a Maria da Boa Morte e a Josélia as eduquei e me pertencem (ANTUNES, 1999, p. 74-75).

Isilda representa a voz do colonizador que se nega a aceitar o fim do domínio português em África. Apesar de sentir que o mundo no qual constituiu sua identidade começa a desabar de forma irreversível, nega-se a abandonar o país e passa a viver isolada, refugiando-se nas lembranças do passado como uma forma de negação a realidade de destruição e miséria que rodeia Angola após o início da guerra civil. Percebe-se, no discurso da personagem, a negação aos crimes cometidos pelo colonialismo, apesar de sua consciência ser constantemente assombrada.

$\mathrm{Na}$ sequência da guerra civil, a fazenda é tomada por guerrilheiros africanos e Isilda se vê obrigada a abandonar as terras já há muito tempo tornadas improdutivas e destruídas pela guerra e parte, juntamente com as duas criadas negras que ainda não haviam fugido da propriedade, Maria da Boa Morte e Josélia, em uma jornada através da destruição de Angola em busca de abrigo contra a violência e miséria que assolava o país. 
Em uma transcrição de 11 de outubro de 1990, ao vagar por entre os escombros e restos de um país devastado pela violência da guerra, Isilda relembra o discurso crítico de seu pai a respeito da colonização da África. Tal passagem é marcante por ressaltar o caráter miserável a que se submeteram os colonos portugueses ao viajarem para outro continente a fim de conquistar riquezas e poderes à custa da exploração do povo africano. No discurso emerge uma dura crítica ao sistema colonial português e ao falso discurso da integração mantido pelo regime do Estado Novo, que pregava que Portugal e as colônias formavam um único povo, irmanado por laços de amizade e cooperação mútua.

O meu pai costumava explicar que aquilo que tínhamos vindo procurar na África não era dinheiro nem poder mas pretos sem dinheiro e sem poder algum que nos dessem a ilusão do dinheiro e do poder que de fato ainda que o tivéssemos não tínhamos por não sermos mais que tolerados, aceitos com desprezo em Portugal (...) o meu pai costumava explicar que aquilo que tínhamos vindo procurar na África era transformar a vingança de mandar no que fingíamos ser a dignidade de mandar (...)

conforme o meu pai costumava explicar

olhavam para nós como criaturas primitivas e violentas que aceitavam o degredo em Angola a fim de cumprirem condenações obscuras longe da família, de uma aldeia qualquer sobre penhascos de onde vínhamos, habitando no meio dos pretos quase como eles, reproduzindo-nos como eles na palha, nos desperdícios, nos dejetos para formarmos uma raça detestável e híbrida que aprisionavam na África (...) (ANTUNES, 1999, p. 246-247).

O discurso de Isilda demonstra que ela se sente extremamente traída pela descolonização e pela independência de Angola. Para ela, a liberdade do povo africano significava o fim do seu tempo de glórias, do tempo em que os brancos portugueses enriqueciam e comandavam o país através de práticas predatórias e segregacionistas, análogos ao modelo escravocrata, presenciado pela relação de poder desigual e exploratória mantida entre os colonos portugueses com os negros africanos, que desempenham, no romance, principalmente a função de criados das casas e empregados das fazendas e plantações. Maria da Boa Morte, Josélia, Fernando e Damião, empregados da família protagonista, são tratados e vistos como objetos por Isilda, numa atitude extremante desumana e racista.

(...) tomem, matem-nos se lhes apetecer, tomem, estamos aqui há vinte ou cinquenta ou cem ou duzentos anos mas tomem, o meu girassol, o meu algodão, o meu milho, a minha casa, o meu trabalho, o trabalho dos meus pais, o trabalho dos pais dos meus pais antes dos meus pais, o lugar dos meus defuntos, tomem, os que mandam em Lisboa decidiram que a minha vida e, mais que a minha vida, a razão dela vos pertencem porque os americanos e os russos dizem que vos pertencem e eles obedecem 
como vocês nos obedeciam a nós com idêntica passividade e idêntica submissão portanto tomem, tomem o que me custou os olhos da cara e os olhos da cara da minha família, o meu gado, o meu café, o meu tabaco, as minhas máquinas, o meu dinheiro no banco, tomem, degolemnos um a um ou enxotem-nos para os barcos de Lisboa, roubem-nos o que não temos no cais (...) (ANTUNES, 1999, p. 276).

Percebe-se que o fluxo de consciência é responsável por desmistificar a falsa harmonia da sociedade colonial portuguesa. Através de um discurso de ódio contra os africanos, que levanta uma espécie de autodefesa dos valores herdados por ela, a personagem mostra-se assombrada com um presente que a rejeita, um novo tempo, um tempo pós-colonial a que ela e sua história deixaram de pertencer e ter poder. Isilda pode ser vista no romance como uma metáfora da sociedade portuguesa que se apegava fortemente aos valores do império, e que com a Revolução, viu-se condenada a um novo tempo, um tempo sem remissão, que, no caso de Isilda, acaba gerando a sua própria morte por negar-se a abandonar a terra africana, há tantos séculos explorada injustamente pelos portugueses.

Como aponta Margarida Calafate Ribeiro (2006), "nos textos de Lobo Antunes (...) narra-se a história daqueles que ficaram de fora do paradigma narrativo dominante" (RIBEIRO, 2006, p. 62), ou seja, em suas narrativas, ganham voz aqueles que foram excluídos pela sociedade e pelo poder estatal, como os colonos portugueses, em $O$ esplendor de Portugal. Ainda segundo as palavras de Ribeiro (2006), “os romances de Lobo Antunes questionam os silêncios que o antigo e o novo regime saído do 25 de Abril fizeram sobre a gesta colonial e o seu trágico fim" (RIBEIRO, 2006, p. 62).

Através da representação dos colonos retornados, O esplendor de Portugal almeja problematizar o silêncio que Portugal manteve sobre o processo de descolonização e o final do império português na África. Publicado duas décadas após a Revolução dos Cravos, o romance almeja a que os portugueses relembrem que as chagas abertas pelo colonialismo ainda estão vivas na memória da nação. Lobo Antunes, em seu romance, através da representação de vários personagens, dá voz a toda uma geração de portugueses que foi esquecida e marginalizada pelo poder estatal e pela sociedade, revelando, assim, que os efeitos da descolonização ainda podiam ser visíveis na identidade nacional através de figuras anônimas, responsáveis pela última viagem do império nacional.

Por meio da voz e da memória dos retornados, os restos do império, Lobo Antunes constrói em $O$ esplendor de Portugal um mosaico da descolonização, mosaico este que, apesar 
de nada esplendoroso, se apresenta como um gesto de questionamento da identidade nacional no período pós-imperial. Percebe-se que a literatura desempenha um papel de destaque na sociedade portuguesa pós-colonial, pois ela se manifesta como uma estratégia de questionamento e reconstrução dos capítulos interditos da história e da memória nacional na contemporaneidade, demonstrando as consequências geradas pelo fim do império português.

\section{Referências}

ABREU, Graça. “O esplendor de Portugal”. In: SEIXO, Maria Alzira et all. Dicionário da obra de António Lobo Antunes. Lisboa: Imprensa Nacional - Casa da Moeda, 2008, 2 v. ANTUNES, António Lobo. O esplendor de Portugal. Rio de Janeiro: Rocco, 1999.

COSTA, Linda Santos. "O romance como crime perfeito". Público, 25 de outubro de 1997, p. 5. In: ARNAUT, Ana Paula. António Lobo Antunes: a crítica na imprensa: 1980-2010: Cada Um Voa Como Quer. Coimbra: Edições Almedina, 2011.

LOURENÇO, Eduardo. O labirinto da saudade. Lisboa: Dom Quixote, 2013.

MATOS, Helena. "Chamaram-lhes retornados". Observador. 11 de abril de 2015. Disponível em: http://observador.pt/especiais/chamaram-lhes-retornados/. Acesso em 14 de dezembro de 2016, às 16h:30m.

MATOS, Helena. "Os retornados começaram a chegar há 40 anos". Observador. 20 de agosto de 2014. Disponível em: http://observador.pt/especiais/os-retornados-comecaramchegar-ha-40-anos/. Acesso em 02 de janeiro de 2017, às 18h:57m.

RIBEIRO, Margarida Calafate. "As ruínas da casa portuguesa em Os cus de Judas e em $O$ esplendor de Portugal, de António Lobo Antunes”. In: Portugal não é um país pequeno: contar o império na pós-colonialidade. Organização: Manuela Ribeiro Sanches. Lisboa: Edições Cotovia, 2006, p. 43-62.

RIOS, Jefferson Del. O esplendor de Lobo Antunes. São Paulo, D’Avila Comunicações. Entrevista com António Lobo Antunes. Revista Bravo, n. 28, jan. 2000.

SEIXO, Maria Alzira. Os romances de António Lobo Antunes. Lisboa: Dom Quixote, 2002.

Data de recebimento: 03/01/2017

Data de aprovação: 28/12/2017 